\title{
HEALTH HAZARDS OF COCONUT OIL - A MYTH OR REALITY?
}

\author{
By \\ B.CHEMPAKAN ${ }^{1}$
}

\begin{abstract}
Coconut oil which forms about 4.9 per cent of the world production of oils and fats, assumes much importance among the common vegetable oils in the world. But the alleged atherogenicity of coconut oibdue to its highly saturated nature hinders coconut oil from having a top position in the world market as an edible oil. The recent classification of oils based on the chain length of fatty auds, as MCT and LCT, reveals the neutral effect of coconut oil, which is also supprted by epidemiological observations. Here the possibilities of labelling cocbout oil as an energy giving non-fattening edible oil is discussed, to dispel the prevailing misconceptions.
\end{abstract}

\section{INTRODUCTION}

India ranks tbird in area and production among the coconut producing countries in the world, with an estimated area of 1.472 million hectares and an annual production-of 8160 million nuts (1988-89). 57 per cent of the coconut production in the country is believed to be used for edible, religious and similar uses, about 8 per cent used as edible and 3.5 per cent as tender coconut. The rest is processed for copra and used for extracting oil, which is the major edible product.

Until a few decades ago, coconut oil was the main fat in large parts of the World and was used without objection. When other vegetable oils like palm oil, soybean oil, sunflower oil, corn oil and cotton seed oil appeared in the world market, coconut oil was pushed back with the alleged reason that it is hyperchlosterolaemic, thus increasing the possible risk of atherosclerosis. People doubtlessly labelled it as the lartery clogging' oil and gave a red signal to its cosumption, due to its highly saturated nature. However, the situation is quite different now. Recent efforts for a deeper insight into the chemistry of dietary fats reveal that hyperchlosterolaernia more or less depend on the fatty acid chain length and related oxidative metabolism. As such, an attempt is made here to dispel the prevailing misconceptions about coconut oil and to label coconut oil as an energy giving non-fattering edible oil.

\section{Chemical features of coconut oil}

Coconut oil is colourless to pale brownish yellow, which is fluid in the tropics and is a solid fat in the temperate climate. It contains 63.3 per cent of the total fatty acids as the saturated medium chain $\left(\mathrm{C}_{6: 0}, \mathrm{C}_{8: 0}, \mathrm{C}_{10: 0}\right.$ and $\left.\mathrm{C}_{12: 0}\right)$ of which 48.3 per cent is lauric acid $\left(\mathrm{C}_{12: 0}\right)$. The oil contains 1.6 per cent linoleic acid $\left(\mathrm{C}_{18: 1}-\mathrm{W}_{6}\right)$ and 6 per cent oleic acid $\left(\mathrm{C}_{18: 1}-\mathrm{W}_{9}\right)$. The percentage of fatty acids in coconut oil are given below:

\footnotetext{
${ }^{1}$ Department of Plant Physiology and Biochemistry, Central Plantation Crops Research Institute, Kerala, India.

- Biochemist, Division of Plant Physiology \& Biochemistry, CPCRI, India.
} 
Fatty acid

$\mathrm{C}_{6: 0}$ Caproic Acid

$\mathrm{C}_{8: 0}$ Caprylic Acid

$\mathrm{C}_{10: 0}$ Capric Acid

$\mathrm{C}_{12: 0}$ Lauric Acid

$\mathrm{C}_{14: 0}$ Myristic Acid

$\mathrm{C}_{16: 0}$ Palmittic Acid

$\mathrm{C}_{18: 0}$ Stearic Acid

$\mathrm{C}_{\text {18:0 }}$ Oleic Acid

$\mathrm{C}_{18: 2}$ Linoleic Acid
Percentage

0.5

7.8

6.7

48.3

18.1

8.8

1.6

The earlier classification of oils and fats based on their degree of saturation is incomplete and unsatisfactory. They can also be categorised based on the length of the carbon chain or the number of carbon atoms present in the fatty acids. Thus the dominant fatty acids present in coconut oil are medium chain triglycerides (MCT) of $\mathrm{C}_{6}$ to $\mathrm{C}_{12}$ group. On the other hand, the fatty acids present in most other vegetable oils and animal fats are long chain triglycerides (LCT) of $\mathrm{C}_{16}-\mathrm{C}_{18}$ group. Keeping this in view, the fatty acid composition of coconut oil is compared with other leading vegetable oils in Table 1.

A closer look reveals that only coconut oil has about 63.3 per cent of MCT whereas other vegetable oils have 70 to 90 per cent LCT containing polyunsaturated fatty acids (POUFA). Despite the increasing demand for palm oil, now-a-days it is classified under LCT, since it contains $80 \%$ of $\mathrm{C}_{16} \mathrm{C}_{\mathrm{I}}$ acids. Thus a reclassification of lipids based on the levels of MCT and LCT is possible which is given below.

\section{CLASSIFICATION OF FATS AND OILS}

\section{I P I D S}

\begin{tabular}{|c|c|c|c|c|c|}
\hline MCT (C6-C12) & \multicolumn{5}{|c|}{ LCT (C-14-C22) } \\
\hline \multirow{2}{*}{ Saturated } & \multirow{2}{*}{ Saturated } & \multicolumn{2}{|c|}{ Mono unsaturated } & \multicolumn{2}{|c|}{ Poly unsaturated } \\
\hline & & W9 Oleic & W6 Linoleic & $\alpha$-linoleic & W3 $\alpha$-linolenic \\
\hline KERNEL OIL & Coco butter & Olive & Corn & Black current & \\
\hline & Dairy fats & Canola & Cotton & & \\
\hline Babassu & Lard & $\begin{array}{l}\text { Sunflower } \\
\text { (hybrid) }\end{array}$ & $\begin{array}{l}\text { Safflower } \\
\text { (Regular) }\end{array}$ & Primrose & Linseed \\
\hline COCONUT & Tallow & & & & \\
\hline Cohune & Palm & Safflower & & Fish & \\
\hline Palm kernel & Stearines & & Sunflower oil & & \\
\hline MCT oil & & & (Regular) & & \\
\hline
\end{tabular}




\section{METABOLISM OF MCT AND LCT}

How are MCT and LCT metabolised in the human body? The intestinal absorption and utilisation of MCT differ a great deai from that of LCT. Stomach as well as intestines contain enzymes which hydrolyze NICT much more rapidly than LCT (Senior et al, 1968). The resulting fatty acids and monoglycerides being highly water soluble arc absorbed even in the absence of bile salts. Due to their small molecular size, MCT can enter the intestinal mucosa without prior hydrolysis. However, within the intestinal cell wall, it is hydrolysed by a mucosal lipase to form medium chain fatty acids and glycerol. The fatty acids arc directly carried through the portal vein to liver, where they are metabolised to release energy, thus simulating the action of carbohydrates. Moreover, MCT does not require carnitine to enter the mitochondria, and hence they are rapidly oxidised to carbon dioxide liberating energy (Blackburn et al, 1988). Thus MCT do not provide a large substrate pool for Very Low Density Lipoproteins (VLDL) which participate in coronary complications and accordingly do not induce fat deposition.

Contrary to this, LCT due to their high molecular weight requires prior splitting before entering the intestinal mucosa. The absorbed fatty acids and glycerol are again resynthesised into triglycerides in the intestine. These are incorporated into chylornicrons and transported into lymphatics and systernic circulation, thus increasing the possible presence of atherogenic lipoproteins.

There are other beneficial effects for MCT. It reduces the serum and liver cholesterol levels that occur when other fats are fed (Kaunitz et al, 1983). It is also suggested in cases of obesity (Bach \& Babayan, 1982). Recent studies by Mascioli et al (1989) show that ingestion of a meal containing MCT results in a higher Resting Metabolic Rate (RMR) indicating greater consumption of energy in calories.

All these points to the fact thlt,t coconut oil, which is highly rich in MCT, acts like a carbohydrate like fuel and is not conducive to fat deposition. It is pertinent herp to note tha $t$ in soybean oil, sunflower oil, cotton seed oil, corn oil and peanut oil having 90 per cent LCT, the MCT content is zero as compared to coconut oil.

\section{RISK FACTORS ASSOCIATED WITH POUFA}

What restrains coconut oil from being a major dietary fat is perhaps the low content of Essential Fatty Acids (EFA). EFA activity is possessed only by POUFA like linoleic, linolenic and arachidonic acids and they are not synthesizable by man. Eventhough the EFA content in coconut oil is low, it can be supplemented by the intake of a variety of foods, particularly fish and leafy vegetables. Thus, when coconut oil is consurned with adequate amounts of linoleic acid, it rules out any possibility in contributing to coronary problems. Soybean oil, sunflower oil, corn oil, peanut oil etc. contain 70-90 per cent POUFA (Table 1). At the same time, excessive amounts of POUFA (more than 10 per cent) is carcinogenic and causes an increased incidence of gall stones (Caroll \& Khor, 1971), and stimulates the ageing process. Due to their higher peroxidation potential, they can also contribute to coronary problems. Moreover, these vegetable oils are rather unfit for consumption in the crude form, due to their unpleasant flavour and taste, even though they are rich sources of carotene and Vitamin E. Refining of these oils, which include degumming, deodorising, bleaching and hydrogenation, results in complete loss of these vitamins. In addition, hydrogenation of these oils converts part of the unsaturated fats to saturated long chain fatty acids and thereby tend to elevate cholesterol levels. But coconut oil, both in its natural state and hydrogenated form, will contain majority of fatty acids as MCTs, which on consumption will not raise cholesterol levels. 


\section{EPIDEMIOLOGY AS A SUPPORT}

The effect of dietary fat on lipid metabolism, especially cholesterol metabolism, has been studied in many countries. Thus, dietary coconut oil alone or when consurned as part of a mixed fat diet appeared to be neutral in terms,of any effect on serum cholesterol as well as liver cholesterol as evidenced by a number of trials conducted in humans (Frants and Carey, 1961; Halden \& Lieb, 1961).

However, conclusive evidence for the nutritional safety of coconut oil is seen from the few epiderniological observations. In a study of two groups of Polynesians, it was found that those consurning coconut oil as 89 per cent of their fat had lower blood pressure ffian those eating 7 per cent. Heart attacks were not observed in either groups (Prior et al, 1981). In another epiderniological report sponsored by the Medical Research Council of New Zealand, Prior (1974) cornpared the serum cholesterol levels of two populations of Polynesian atolls (Pukapukans and Rarotangans) having $75 \%$ and $25 \%$ of their diet as coconut oil. He found that Pukapukans who ate more coconut oil in their diet and fat overall, had lower serum cholesterol levels than Rarotangans.

Dietary surveys conducted in recent years inoicated that atherosclerosis is more extensive among Japanese who had settled in North America and had adopted the American way of life, than the Japanese living in Japan (Wickramanayake, 1988). Heart attacks are rare in the rural folk and also people living in urban areas of Sri Lanka, who use coconut daily in their food preparations (Atukoralae, 1987). Among the Nicobar Islanders, whose staple food comprises mainly coconut and coconut products, incidence'of coronary heart disease is comparatively less.

These observations and other evidences suggest that coconut is not atherogenic, if used as a major dietary fat. The recent theory of platelet aggregation in atherosclerosis again proves that coconut oil does not contribute to the triglyceride portion of LDL with subsequent formation of platelets.

In short, the alleged atherogenicity of coconut oil has to be cleared out and its nutritional safety has to be brought into limelight. Attempts should be made to declare the fats and oils on the basis of MCT andl LCT, rather than the degree of saturation. However, condemnation of a fat like coconut oil, simply based on its saturation, ignoring its other characteristics, seems to be highly misleading. The myth has to be dispelled and an awareness created in common man on the benefits of consuming coconut oil.

\section{ACKNOWLEGEMENT}

The author is grateful to Dr. M.K. Nair, Director and Dr. V. Rajagopal, Head, Division of Plant Physiology and Biochemistry, Central Plantation Crops Research Institute, Kasaragod, India, for critically going through the manuscript and for providing valuable suggestions. 


\section{REFERENCES}

ATUKORALE, D.P. 1987. Coconut, cholesterol and heart attacks. Coconut Bulletin, 4(1): 35.

BACH, A.C. and BABAYAN, V.K. 1982. Medium chain Triglyerides: An update. American Journal of Clinical Nutrition, 36: 950-62.

BLACKBURN, C.K. et al. 1989. A reevaluation of coconut oil's effect on serum cholesterol and atherogenesis. Journal of Philippine Medical Association, 65(1): July-September.

CARROLL, K.K., KHOR, A.T. 1,971. Effects of level and type of dietary fat on incidence of mammary,tumours induced in fenyale, Sprague Dawley rats by 7, 12-dimethyl benz (alpha) anthracene, Lipids, 6415.

FRANTZ, I.D. CAREY, J.B. 1961. Cholesterbl content of human liver after feeding of corn oil and hydrogepierated coconut oil, Proc. Soc. Exp. Biol. Med., 106: 800-1.

HALDEN, V.W., LIEB, H. 1961. Influence of biologically improved coconut oil product on the blood cholesterol levels of human volunteers. Nutr. Dieta, 3: 75-88.

KAUNITZ, H. 1983. Biological and therapeutic effects of "MCT" (Medium chain Triglyuride) from coconut oil. Coconuts Today, 1(2).

MASCIOLI, E.A. et al. 1989. Serum Fatty acids after intravenous Medium chain Triglyceride Administration, Lipids, XXIV(9).

PRIOR, I.A., DAVIDSON, F., SALMOND, C.E. and CZOCHANSKA, Z. 1981. Cholestrol, coconuts and diet on Polynesian atolls - a natural experiment: the Pakapuka and Tokelau island studies. Am. J. Clin. Nutr., 34: 1552-61.

PRIOR, I.A.M., 1974. Cardiovascular epiderniology in New Zealand and the Pacific. Nz. Med. J., 80: $245-52$.

SENIOR, J.R., VAN, ITALLIE, T.B. and GREEN BERGER, J., Eds. Medium chain Triglyeride Univ. of Pennsylvania Press, Philadelphia, 1968.

WLCKRAMANAYAKE, T.W., 1988. The coconut and heart disease. Indian Coconut Journal, XIX (2): 9-12. 
Table 1. Fatty acid compostion of coconut oil as compared to othe common edibles oils (Soybean oil, palm oil, corn oil, safflower oil, sunflower oil, peanut oil)

\begin{tabular}{|c|c|c|c|c|c|c|c|c|c|}
\hline & & Fatty acid & $\begin{array}{c}\text { Coconut } \\
\text { oil } \\
\end{array}$ & Palm oil & $\begin{array}{c}\text { Sunflower } \\
\text { oil } \\
\end{array}$ & Corn oil & $\begin{array}{c}\text { Soybean } \\
\text { oil } \\
\end{array}$ & $\begin{array}{c}\text { Safflower } \\
\text { oil } \\
\end{array}$ & Peanut oil \\
\hline \multirow{5}{*}{$\begin{array}{l}\text { Medium } \\
\text { Chain } \\
\text { Fatty } \\
\text { Acids }\end{array}$} & Saturated & & & & & & & & \\
\hline & C6-Caproic & & 0.5 & - & - & - & - & - & - \\
\hline & C8-Capvylic & & 7.8 & - & - & - & - & - & - \\
\hline & C10-Capric & & 6.7 & - & - & - & - & - & - \\
\hline & C12-Lauric & & 48.3 & 0.2 & 0.5 & - & - & - & - \\
\hline \multirow{11}{*}{$\begin{array}{l}\text { Long } \\
\text { Chair } \\
\text { Fatty } \\
\text { Acids }\end{array}$} & C14-Myristic & & 18.1 & 1.1 & 0.2 & - & - & 0.1 & 0.1 \\
\hline & C16-Palmitic & & 8.8 & 44.4 & 6.8 & 11.5 & 11.0 & 6.5 & 11.6 \\
\hline & C18-Stearic & & 2.6 & 4.5 & 4.7 & 2.2 & 4.0 & 2.4 & 3.1 \\
\hline & C20-Arachidic & & - & - & - & 0.2 & - & 0.2 & 1.5 \\
\hline & C22-Behenic & & - & - & - & - & - & -3.0 & \\
\hline & C24-Lignoceric & & - & - & - & - & - & - & 1.0 \\
\hline & Unsaturated & & & & & & & & \\
\hline & C16-1 Palmitoleic & & - & 0.1 & 0.1 & - & 0.1 & - & - \\
\hline & C18:1 Oleic & & 6.2 & 39.2 & 18.6 & 27.5 & 23.9 & 13.1 & 0.2 \\
\hline & C18:2 Linoleic & & 1.6 & 10.1 & 68.6 & 57.8 & 53.2 & 77.7 & 46.5 \\
\hline & C18:3 Linilenic & & - & 0.4 & 0.5 & 0.8 & 7.8 & - & 31.4 \\
\hline
\end{tabular}

